\title{
Vienne (Isère)
}

Square Albert-Vassy (arcades du forum)

\section{Monique Zannettacci}

\section{(2) OpenEdition}

12 Journals

Édition électronique

URL : http://journals.openedition.org/adlfi/7037

ISSN : 2114-0502

Éditeur

Ministère de la culture

Référence électronique

Monique Zannettacci, «Vienne (Isère) », ADLFI. Archéologie de la France - Informations [En ligne], RhôneAlpes, mis en ligne le 01 mars 2007, consulté le 20 avril 2019. URL : http://journals.openedition.org/ adlfi/7037

Ce document a été généré automatiquement le 20 avril 2019.

(c) Ministère de la Culture et de la Communication, CNRS 


\title{
Vienne (Isère)
}

\author{
Square Albert-Vassy (arcades du forum)
}

\section{Monique Zannettacci}

\section{Identifiant de l'opération archéologique : 229625}

Date de l'opération : 2007 (SU)

1 Les éléments conservés de l'angle sud-est du forum étaient intégrés jusqu'au XVIII ${ }^{\mathrm{s}} \mathrm{s}$. dans le « Palais des Canaux » et la "Tour d'Orange », château médiéval dont il subsiste le mur d'enceinte polygonal et une porte accolée à l'arcade nord-sud. Les observations archéologiques préalables à la restauration de ce monument classé, dans le cadre du Plan patrimoine de la ville, ont permis de préciser la technique de construction et la chronologie des deux arcades du forum en élévation (M. Zannettacci, D. Fellague, docteure, spécialiste de décor architectural romain).

2 Les deux arcades sont en calcaire du Midi et ornées sur leurs deux faces. L'arcade nordsud, dernière d'une rangée d'arcades qui se poursuivait au nord (un départ d'arc a été dégagé par la restauration), est interprétée comme un des éléments subsistant d'une galerie derrière laquelle se développait la basilique du forum. La grande arcade est-ouest est une entrée du forum (située au nord) ; au sud, une place dallée en contrebas de marches (au sud et à l'ouest) occupe l'angle formé par les deux arcades.

3 L'arcade nord-sud utilise une technique de construction particulière et méconnue pour la mise en place d'un pilier à l'est et d'une partie des tambours de demi-colonnes à l'ouest. La profusion du décor de la frise ouest trouve peu d'équivalent (anthémion avec des palmettes acanthisées variées; têtes en saillie au-dessus des supports). Ces têtes ne sont pas des Jupiter Ammon, comme on le lit souvent, mais probablement des têtes de satyre et de ménade (Fig. $n^{\circ} 1$ : Tête scultée). Le décor de la face orientale, mal conservé, a été précisé (pilastre angulaire avec un chapiteau corinthisant, architrave et frise dont il reste des traces ténues). Un mur est-ouest, appliqué contre l'extrémité sud la face orientale de la petite arcade, fermait l'espace. 
4 La grande arcade est-ouest, en calcaire du Midi comme la petite, est cependant postérieure, et appliquée sans liaison contre la petite. L'observation des cavités (trous de pince et trous de louve) sur les blocs montre que ce sont des éléments de remploi. L'adjonction de la grande arcade a imposé la retaille de certaines parties de la face occidentale de la petite arcade, du soubassement à l'entablement, ainsi que le creusement de faux joints pour donner l'impression d'une unité entre les deux monuments. Ce souci d'homogénéité se perçoit à travers le décor de la grande arcade qui imite celui de la petite arcade (colonnes, architrave et corniche) ; la frise n'a pas reçu de décor.

5 L'analyse stylistique permet de proposer une chronologie pour ces monuments qui restaient mal datés. La petite arcade semble d'époque julio-claudienne. La grande arcade est construite en imitation de la première, ce qui ne facilite pas la datation; quelques détails des motifs autorisent cependant à proposer un terminus post quem à l'époque flavienne.

6 Au nord de la petite arcade et dans son prolongement, la porte médiévale du palais des Canaux est ornée à l'ouest de deux éléments différents : une tête sculptée qui semble une imitation du Bas-Empire des têtes de la frise ouest, et un buste de personnage couvert d'un manteau à capuchon qui pourrait être de la fin du Moyen Âge ou de la Renaissance. La porte a conservé des éléments de fermeture, et a été percée en un second temps de meurtrières destinées aux armes à feu. Le mur polygonal qui constituait l'enceinte du palais des Canaux rejoint le mur nord en élévation de la Salle d'assemblée située au sud du forum. Les angles du mur polygonal sont retaillés dans des remplois de la pierre calcaire utilisée pour les arcades; certaines de ces pierres portent les motifs repérés sur les architraves. Ce château existait au haut Moyen Âge, mais l'état visible aujourd'hui pourrait dater de la fin du XIII s., à l'époque du partage entre la manse épiscopale et la manse capitulaire (1285): le palais des Canaux revient alors aux chanoines de SaintMaurice.

7 ZANNETTACCI Monique

\section{ANNEXES}


Fig. $\mathrm{n}^{\circ} 1$ : Tête scultée

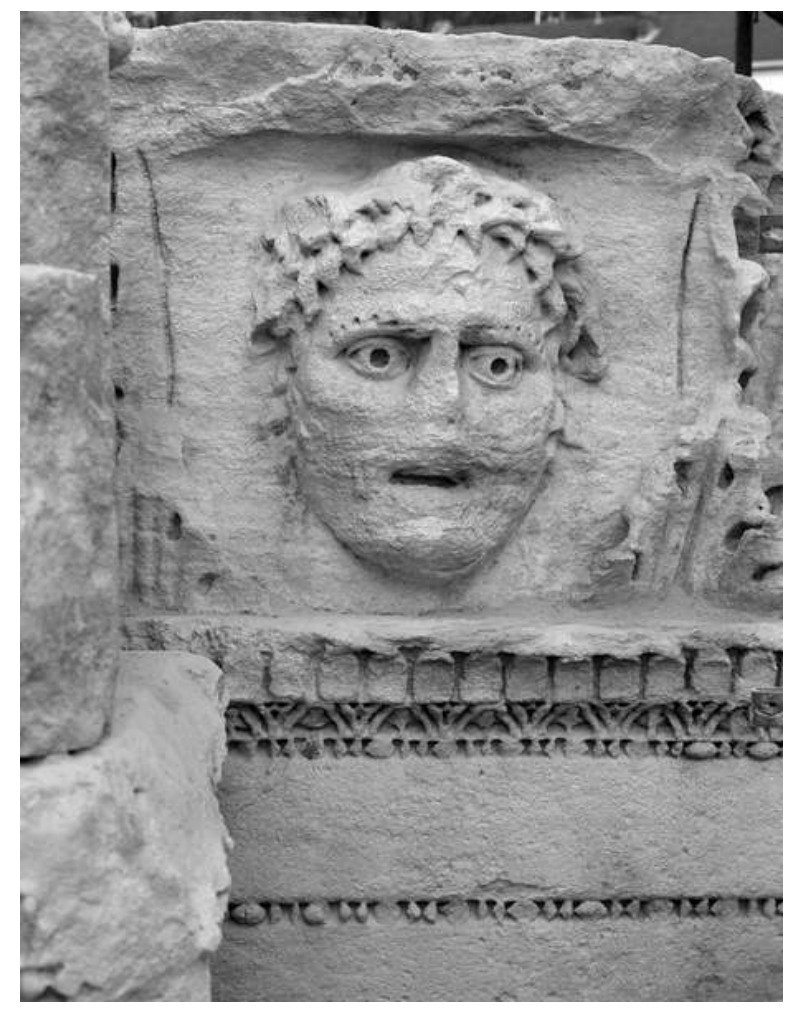

Auteur(s) : Zannettacci, Monique. Crédits : ADLFI (2007)

INDEX

Index chronologique : Julio-claudien, Bas-Empire, Empire romain, Moyen Âge, Ier siècle apr. J.C., XIIIe siècle apr. J.-C.

Index géographique : Rhône-Alpes, Isère (38), Vienne (86)

operation Sauvetage urgent (SU)

\section{AUTEURS}

MONIQUE ZANNETTACCI

COL 